\title{
A STUDY OF VADRINE, ALONE AND COMBINED WITH SULPHETRONE
}

\author{
by \\ Dr. R. BRECHET, M.1). \\ Caluquembe, via Vila Mariamo Machado, Angola \\ and \\ Dr. R. G. Cochrane, M.D., F.R.C.P., D.T.M.\&u. \\ 11 a Weymouth Street, London, W.1
}

\section{Introduction}

Vadrine of Messrs. Geistlich Ltd. has been reported on previously by Jopling, W. H., and RidLeY, D. S., in 1958, who tried it in leprosy patients. It is 2-pyridyl- (4)-1, 3, 4,-oxydiazalone-(5) p-amino salicylate with the following formula:

In the Philafrica Mission in Angola in September 1955 we also began a trial of this drug and treated 40 cases up to May 1960 . We have chosen to report on 20 of these cases, mainly because the lepromatous element was important in these 20 cases. For primary drug trials we think that tuberculoid cases should not be selected, because there is a tendency to spontaneous healing in tuberculoid cases, and it is not easy to give a fair clinical assessment. The 20 selected cases have been treated for an average period of 33 months (18 to 50 months). The usual physical and laboratory examinations were given to all cases. During the trial the bacterial index was estimated every 3 months, and photographs and skin biopsies were taken every 6 months. The average dose given of Vadrine was $30 \mathrm{mg} . / \mathrm{kg}$. of body weight, as the optimum dose appears to be between 30 and $40 \mathrm{mg} . / \mathrm{kg}$.

Lepromatous reactions of the ENL type occurred in 6 of the 20 selected cases, and there were milder reactions in 6 others. Mild anaemia occurred under treatment in 8 cases, but this improved without the exhibition of iron. There was 1 case with marked anaemia. There was 1 case of nephritis which responded well to ordinary treatment and which seemed to have no relationship to the taking of Vadrine. A sensation of burning in the feet and sometimes in the legs was the only possible symptom relatable to the drug. This occurred in 8 cases during the 2 nd and 3 rd years of treatment. There were breaks in the treatment of 3 cases, leading to serious clinical and bacterial index deterioration. The replacement of Vadrine produced a definite improvement in each case. In most cases under treatment lepromatous lesions flattened and the infiltrations progressively disappeared. In 3 cases ulcer healing was prompt after Vadrine had been begun. On Vadrine all the patients felt better and fitter. Bacilli showed changes in form and tended to become beaded, 


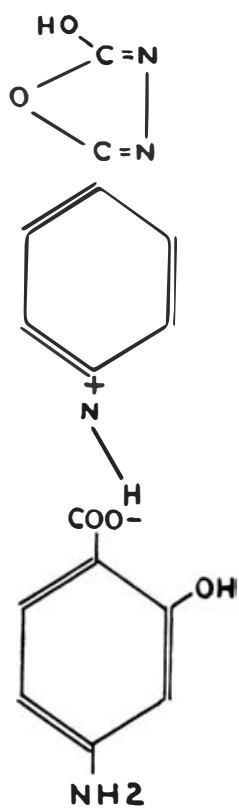

and histological improvement was present but slower, appearing at least 1 year after the beginning of treatment. General improvement after the first year was less spectacular but it continued slowly. Results after the second year were classified as follows, excellent in 3 , good in 4 , satisfactory in 7 , stationary in 5 , and bad in 1 . In 10 cases the lepromin reaction became slightly positive, after being negative at the beginning, and in 4 of these 10 cases there was a greater predominance of the dimorphous features along with the lepromin test improvement. We think that most leprosy cases pass through a "dimorphous zone", in evolution either towards lepromatous or tuberculoid leprosy. Such cases as transform into lepromatous leprosy show dimorphous features previously masked by the lepromatous element as the latter begins to clear. In such circumstances, as these cases pass into the atypical tuberculoid zone of the dimorphous spectrum one would expect the lepromin reaction to transform from a negative to a positive.

Fig. 1 shows a graph of the improvement under Vadrine treatment. It will be noted that in the first 6 to 12 months the bacterial improvement under Vadrine was comparable to that under DDS, but after 12 months, the improvement began to lag behind that seen under DDS and Ciba-1906. After 18 months the improvement curve tended to remain level. Of the 20 cases, 4 had no relapse up to this time and 2 were stationary with an eventual slight deterioration. The 12 other cases showed clinical deterioration after 22 months of treatment with Vadrine alone. The earliest relapse occurred 14 months after the beginning of treatment and the latest was at 36 


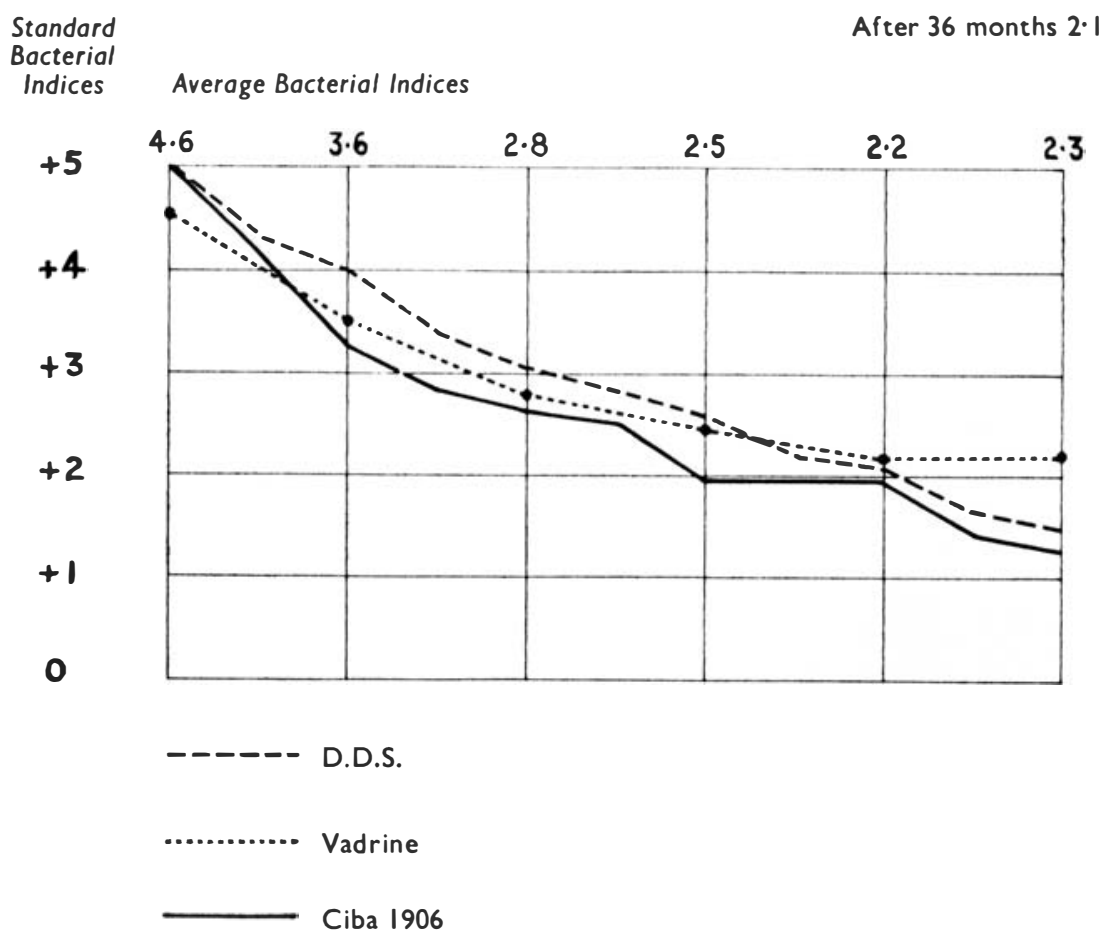

FIG. 1. Chart Showing the Average Bacteriologicai Index of 18 Cases on Vadrine Therapy at six-monthly intervals.

months. One case had 47 months' treatment without any evidence of deterioration. Clinical deterioration preceded bacterial or histopathological and showed itself by new lesions appearing and old lesions exacerbating. Hence we thought that Vadrine should be combined with Sulphetrone in the hope of preventing the resistance to Vadrine which appeared after about 18 months. We found evidence that this was so.

\section{Illustrative cases}

Because there is not space for all cases, notes of 2 cases under treatment are here given. 1 under Vadrine alone, 1 under Vadrine plus sulphetrone.

\section{Case under Vadrine Treatment alone}

Case 1. Feliz Chissingui. No. 658, Jamba. Male, aged 35 years.

This patient was admitted into the leprosarium on 26th November, 1956. Macules had appeared on the right arm and thigh a year prior to admission. On examination the body was seen to be covered with small diffuse macules, typical of lepromatous leprosy, small nodules on the edge of the ears, and infiltration of the lobes of the ears was also seen. Treatment commenced in February 1957, and the dosage given was $1200 \mathrm{mgms}$. daily, that is $22 \mathrm{mgm}$./ kg.body weight. The following is the histopathological report on the biopsy taken before treatment began. 
Patients under Vadrine alone (FELIZ) and Vadrine plus

Sulphetrone (NAVAYA)

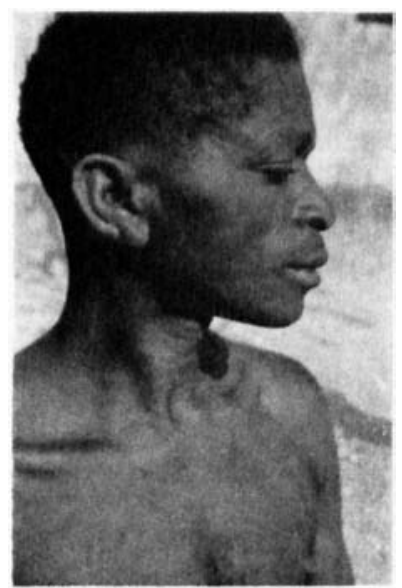

FELIZ Dimorphous

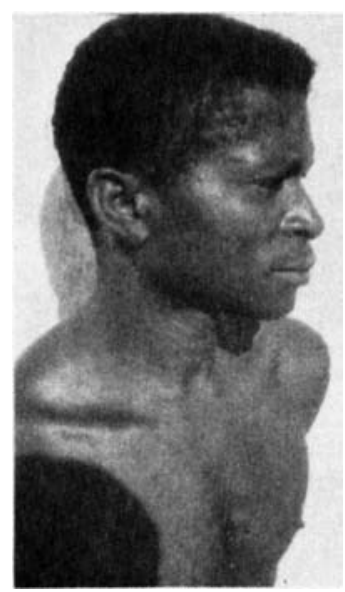

FELIZ Healing leproma

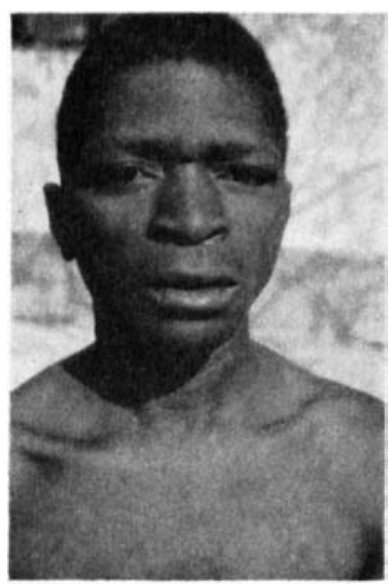

FELIZ Dimorphous

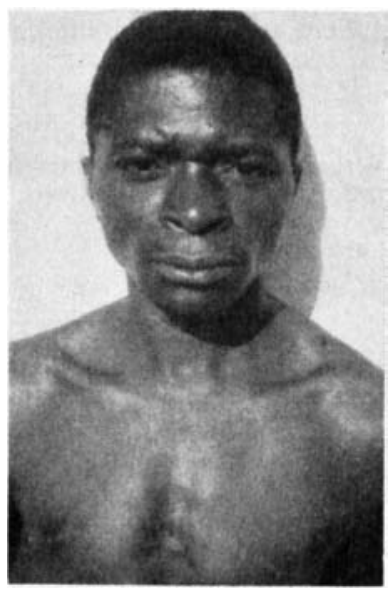

FELIZ Healing leproma

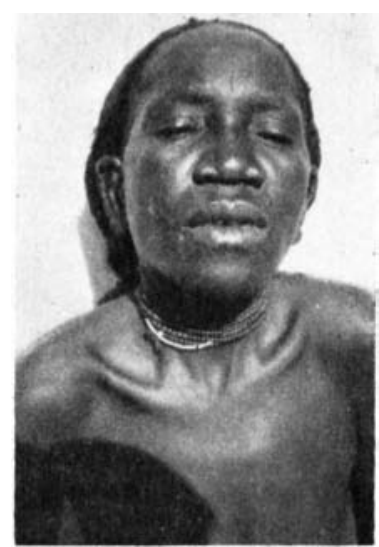

NAVAYA Leproma

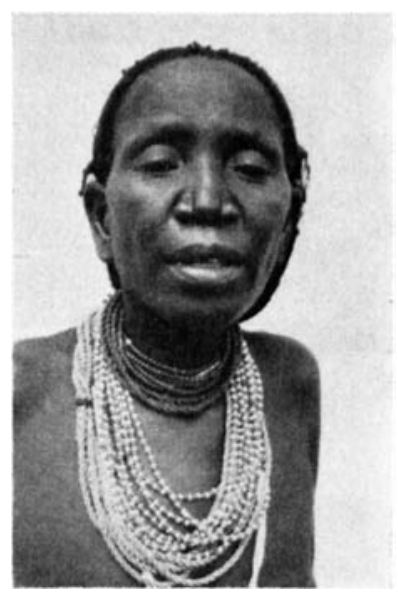

NAVAYA Leproma, commencing resolution 
Lab. No. 2596.

H.E. Section: A gross infiltration is seen with a relatively clear sub-epidermal zone. The granuloma consists of well-developed macrophages and considerable round celled infiltration is seen. These round cells occur in collections and among them are fairly numerous plasma cells. In one area near to a hair follicle and fairly superficial there is a small focus with round cells in the periphery and epithelioid cells in the centre. There is some evidence of foamy cell change, but this is not conspicuous. Nerves, generally speaking, are well-seen and uninvolved. However, there are some nerves in which there is a certain amount of cellular involvement, but in the Fite Faraco section the increase of the cellular infiltrate appears to be largely in cells of Schwann.

F.F. Stain: Fairly numerous acid-fast bacilli seen throughout the section, showing no morphological change.

Diagnosis: This is an active case with lepromatous features. Activity is shown by the presence of fairly numerous plasma cells, but there is also some evidence of epithelioid cell formation and round celled infiltration which is much more than one would ordinarily see. There is also further evidence of a commencing lymphocytic response. Nevertheless, the histology is predominantly lepromatous.

In April 1957 it was noted that, while there was some clinical improvement, macular lesions were more evident and were slightly elevated, and definite paraesthesia developed on the extremities. In August 1957 the patient showed blisters on the feet and on the right hand. There was also some reaction on the ears, which had become swollen and showed some desquamation and crust formation. The macules had changed their characteristics somewhat, and showed elevation and some erythema. The biopsy report on tissue taken in August 1957 was as follows:

Lab. No. 2847.

H.E. Section: There is a massive infiltration occupying about 80 per cent. of the total area of the corium with a relatively clear sub-epidermal zone. The granulomatous infiltration consists almost entirely of epithelioid cells with, here and there, an occasional giant cell. Amidst this epithelioid granulomatous tissue there are foci of round cells and plasma cells, but there is no true tubercle formation. Nerves are quite unrecognizable.

F.F. STAIN: Scanty acid-fast bacilli seen here and there in the section and are generally arranged singly and show no morphological change.

Diagnosis: This is a very active dimorphous lesion towards the tuberculoid end of the spectrum rather than the lepromatous, although the tuberculoid features-except for the fact that most of the cells are epithelioid with an occasional giant cell-are not very marked.

A photograph was taken in August 1957 and showed definite macular lesions on the chest. Unfortunately, the first photograph, taken before therapy commenced, was lost in the post. In January 1958 there was considerable improvement and the macular lesions were much less conspicuous. The following is a biopsy report on tissue taken in January 1958:

Lab. No. 2955.

H.E. Section: A diffusely scattered infiltration is seen underneath the epidermis of moderate intensity, extending into the deeper parts of the corium, but in this area the infiltration is only slight. The infiltration consists largely of histiocytes and round cells, and there is some evidence of foamy cell change. In one area in the vicinity of a hair follicle round celled infiltration is more marked. 
F.F. Siain: No acid-fast bacilli seen.

IIAGNOSIS: In the absence of definite acid-fast bacilli this is a difficult section on which to give a diagnosis, but the picture is consistent with a resolving lepromatous lesion. The fact that there do not seem to be any nerves cut across in the section might suggest a previous dimorphous lesion, ${ }^{*}$ but in the absence of evidence onc must conclude that the biopsy is taken from a resolving or healing lerpomatous case.*

* It is to be noted that biopsy readings are made without access to clinical notes and, therefore, I (R.G.C.) would not know when I gave the report, the findings of the previous biopsy-2847.

The patient continued to make substantial progress. He was taking 1,200 mgms. Vadrine daily until 1959, when he started taking 1,600 mgms. daily.

The bacteriological indices were as follows:

January $1957-5.0$
March $1957-1.1$
August $1957-0.5$

5 negatives were then recorded.

November 1958 - 0.1

From October 1959 to January 1960 all bacteriological investigations were negative.

The Mitsuda reaction in January 1957 was negative, and in February 1959 it was slightly positive. A biopsy of the lepromin reaction showed essentially lepromatous histology.

\section{Comments}

In the first instance this case appeared to be lepromatous, but with treatment the lepromatous features began to subside and the previous dimorphous lesions that were masked by the ascendancy of the lepromatous element in dimorphous leprosy began to assert themselves. It is interesting to note that the lepromin reaction changed from a negative reaction to a slightly positive reaction. This need not have been significant, for the biopsy of the lepromin reaction in 1959 indicated essentially lepromatous features, but, nevertheless, there was in all the biopsies some indication of a dimorphous element in the tissue response - the patient remaining negative up to May 1960.

\section{Vadrine plus Sulphetrone ( 50 per cent aqueous solution) Treatment}

Case 5. Navaya Nanga, No. 627, Jamba. Female, aged 45 years.

This patient was admitted into the leprosarium in August 1955. It was stated that the first signs of leprosy were noted a year previously, when the patient felt a sensation of heat in the body. In May 1955 tiny nodules appeared on the face. After a time her condition deteriorated and she applied to the institution for admission. On admission she patient presented the following clinical signs: gross nodulation of the ears, smaller nodules on the face, partial loss of the eyebrows and some infiltration of the forearms, but no nodulation of the trunk. The lepromin test was negative to both reactions. The following is a report on tissue taken at the time of admission:

Lab. No. 2368.

H.E. Section: There is a gross infiltration throughout the epidermis, leaving a moderately narrow, free, sub-epidermal zone. The infiltrate consists of 
macrophages and round cells. Plasma cells are not conspicuous. The nerve changes are interesting in that there is marked proliferation of the perineurium and yet the nerve shows considerable cellular invasion. Foamy cell change is not conspicuous.

F.F. Srain: Fairly numerous acid-fast bacilli seen with little morphological change.

Diagnosis: This section is probably taken from a lerpomatous case although the histological evidence suggests that it may be very near to the borderline end of the lepromatous spectrum.

It will be noted that mention has been made of the state of the nerves in the tissues, indicating that they showed more cellular infiltration than one would normally expect to see in a straight lepromatous case, and, therefore, it is suggestive that the patient had passed through the dimorphous zone in the evolution of the disease towards lepromatous leprosy, as so often happens in our experience.

The patient commenced Vadrine therapy on 28th September 1956 having had no appreciable treatment with DDS previously. She was given 1,200 mgms. Vadrine daily during the first two months, followed by $1,600 \mathrm{mgms}$. daily, which is $30 \mathrm{mgms}$. $/ \mathrm{Kg}$. body weight. A biopsy was taken in January 1957 and the following is the report:

Lab. No. 2600.

H.E. Section: There is a moderate to gross infiltration seen underneath the epidermis, leaving a relatively clear sub-epidermal zone. In the superficial parts of the dermis the infiltrate is seen and consists of a small area of foamy cell change amidst which there is seen fairly numerous round cells. As one looks deeper into the dermis the granulomatous infiltration becomes more marked and extends to the subcutaneous fatty tissue. Amidst the foamy cells are numerous round cells and a few plasma cells. Nerves, while not grossly invaded, show considerable cellular increase and some infiltration between the nerve bundles. There is considerable proliferation of the epineurium.

F.F. Stain: Fairly numerous acid-fast bacilli seen, showing gross morphological change.

DiAGNosis: This has the appearance of a moderate lepromatous lesion, showing commencing resolution under therapy.

The next biopsy was taken in April 1957 and showed comparatively little alteration:

Lab. No. 2817.

H.E. Section: There is a generalized infiltration throughout the corium, leaving a narrow, relatively clear, sub-epidermal zone. The granulomatous infiltrate occupies about 60 per cent of the whole of the corium. The infiltrating cells are chiefly histiocytes and macrophages. There is a certain amount of foamy cell change. Here and there are more definite foci. These are associated with the skin appendages and consist of epithelioid and round cells and an occasional small giant cell. Nerves, by and large, are well seen, although there is considerable increase in Schwann cells. The epithelioid foci appear as if they are in connection with a nerve, but no nerve tissue is discernible.

F.F. STAIN: Acid-fast bacilli are seen throughout the section in moderate numbers except in areas where there are epithelioid cells. The M.leprae show some morphological change.

DIAGNOSIS: This is a lepromatous case showing some activity, with evidence that it either shows dimorphous signs clinically or else it has passed from dimorphous leprosy to lepromatous leprosy. I do not think there is enough 
evidence to say that it is a dimorphous case on the lerpomatous side of the spectrum. There is some evidence of the influence of therapy, as the M.leprae look to be rather broken up.

It is interesting to note that the biopsy report suggests that the dimorphous features, which may have originally been manifest, have now been completely suppressed, as the patient passed into lepromatous leprosy. A biopsy was taken six months later in October 1957. This showed that practically all the bacilli had disappeared. The following is the report:

Lab. No. 2909.

H.E. Section: There is a diffusely scattered infiltration of slight to moderate intensity underneath the epidermis. While the sub-epidermal zone is relatively free from infiltration, there is no clear-cut free space. The infiltrating cells are chiefly round cells and histiocytes, but there is some evidence of a concentration of the cellular infiltration around the appendages of the skin, particularly the hair follicles. Nerves are recognizable, but there is a considerablc cellular increase (round cells and histiocytes), but no definite tuberculoid structure or characteristic proliferation of the perineurium as seen in lepromatous lesions.

F.F. Stain: There was one acid-fast bacillus seen in a nerve.

Diagnosis: This is a difficult section to interpret, but it is obviously a lesion improving under therapy. While there are no definite dimorphous features in the section, the fact that the nerves show a greater cellular increase than one would normally find in lepromatous leprosy is suggestive that this is a healing case with evidence of residual dimorphous lesions.

Subsequent to this, the patient's condition began to deteriorate. First, very occasional acid-fast bacilli appeared in the section. Many of these bacilli were not granular, but were well developed, indicating that the patient's clinical condition had deteriorated, and that the bacilli were returning to the rod-shaped form. This was further evidence that Vadrine probably had had its maximum effect.

\section{Conclusions}

During the experimental period of 4 years, we found that Vadrine appeared to have a definite action in lepromatous leprosy during the first 2 years, the results being comparable to, or slightly better than those seen in DDS therapy over a similar period. The effect of the drug becomes less obvious at the end of 2 years and little improvement is seen after that time.

We think that Vadrine has advantages in its rapid action in the first 12 to 18 months, its lack of toxicity and side effects and its reactions are at a minimum. The optimum dose of Vadrine seems to be 30 to $40 \mathrm{mg} . / \mathrm{kg}$. body weight. We found evidence that Vadrine is useful in those cases which show intolerance to sulphone therapy. We think that it is inadvisable to continue Vadrine therapy for more than 2 years. There is some evidence that combination with sulphones prolongs the useful period, but this evidence is not yet conclusive. On signs appearing of clinical and bacterial deterioration we think a change of treatment is advisable. 
In addition to Vadrine being a useful initial treatment in cases which show intolerance to sulphone therapy, we think there is also some evidence that even after 2 years its combination with sulphones enhances the effectiveness of the therapy.

We point out that no drug has yet been discovered which is uniformly successful in every case of leprosy. The sulphone group of drugs are of great value in most cases of leprosy but there are still a few patients who tail to respond to them by adequate improvement and about 10 to $16 \%$ do not respond at all. Alternative drugs are called for in this group of cases and it would seem that Vadrine could be used as one of these drugs, either alone or in combination with one of the sulphones, our preference being parenteral Sulphetrone. It looks as if the therapy of leprosy is now beginning to run parallel to that of tuberculosis, and the logical approach to the treatment of an active lepromatous case is to use a rapidly-acting drug such as Etisul for 3 months, followed by Vadrine, combined with one of the sulphones (probably Sulphetrone). Finally, at the end of 2 years of continuous treatment with Vadrine and Sulphetrone, the patient may be put on diphenylthiourea (Ciba-1906). For the adequate approach to the therapy of leprosy it is essential that the physician should have a number of drugs available so that he may change or combine them in order to avoid drug resistance.

\section{Acknowledgments}

We express our appreciation to Geistlich \& Sons Ltd., Wolhusen, Switzerland, for their supply of Vadrine (S131) used in this trial.

\section{Reference}

Jopling, W. H., and RidLey, D. S. (1958), Leprosy Review, 29, 3, July 1958, p. 143-147. 